\title{
La participación del cooperativismo en las políticas públicas
}

\author{
Vega María Arnáez Arce \\ Doctora en Derecho. Profesora de Derecho Administrativo. \\ Facultad de Derecho. Universidad de Deusto
}

Recibido: 11.05 .2012

Aceptado: 20.06.2012

Sumario: I. Introducción. II. La participación en el derecho administrativo: 2.1 Significado de la participación ciudadana en la gestión púbica. 2.2 Participación y planificación de las políticas púbicas. III. Cooperativismo y participación: 3.1. Aproximación al concepto jurídico básico de las cooperativas como empresas de participación. 3.2. Institucionalización de la participación del cooperativismo en las políticas públicas. El supuesto del Consejo Superior de Cooperativas de Euskadi. IV. A modo de conclusión. V. Bibliografía.

Resumen: En el presente trabajo se aborda una de las manifestaciones más destacadas de la evolución del Derecho administrativo de nuestros días: su apuesta por la interacción con los ciudadanos que demandan, cada vez más, un papel activo y mayor participación en la planificación, la ejecución y la evaluación de las políticas públicas. En este sentido, se propone una aproximación al significado, alcance y articulación de la participación del cooperativismo vasco en las políticas públicas, a través de su máximo órgano de representación, el Consejo Superior de Cooperativas de Euskadi.

Palabras clave: participación y gestión democrática, gestión pública, planificación participativa, coordinación, Consejo Superior de Cooperativas de Euskadi.

Abstract: This work tackles one of the most outstanding manifestations of the evolution of administrative law at the present time: its focus on interaction with citizens who are demanding an increasingly active role and greater participation in planning, executing and assessing public policy. The study proposes a closer look at the meaning, scope and organisation of Basque cooperative participation in public policy through its leading representative body, the Cooperative Board of Euskadi.

Key words: participation and democratic management, public management, participative planning, coordination, Cooperative Board of Euskadi. 


\section{Introducción}

En el contexto actual de una economía global en el que nos vemos inmersos, la crisis financiera y económica internacional que nos afecta exige que tanto las Administraciones y demás entidades del sector público como los agentes económicos privados aúnen sus esfuerzos en torno a la recuperación económica y para la consolidación de los aspectos más sólidos y estables de nuestro modelo productivo'1.

Desde los primeros años del siglo XXI, vivimos inmersos en un entorno cada vez más cambiante, en el que se vienen sucediendo importantes transformaciones económicas, sociales y también políticas, que llevan implícitas una necesidad inminente y creciente de reconfiguración de las Administraciones Públicas, de su organización y de su funcionamiento².

En este sentido, existe en la actualidad una estrategia clara, a nivel internacional, europeo, estatal y autonómico, que trabaja por la innovación de las Administraciones Públicas como elemento clave para potenciar su competitividad, eficacia y eficiencia y que apuesta por la interacción con los ciudadanos que demandan, cada vez más, un papel activo y mayor participación en la planificación, la ejecución y la evaluación de las políticas públicas.

En este sentido, y como ejemplo de participación y gestión democrática, destaca el fenómeno cooperativista, basado en los valores de solidaridad, democracia, igualdad, equidad, autoayuda y auto-responsabilidad, hasta el punto de poderse afirmar que lo que singulariza a las entidades cooperativas no es su objeto social o la concreta actividad que desarrollan, sino su esencia y principios rectores e inspiradores básicos. Concretamente, los siguientes: la adhesión voluntaria y abierta de sus miembros, su gestión democrática y la participación económica de sus socios, su autonomía e independencia, la educación, formación e información y, finalmente, la cooperación entre cooperativas junto con el interés por la comunidad que les sirve de base ${ }^{3}$.

1 Véase en este sentido el Preámbulo de la Ley 2/2011, de 4 de marzo, de Economía Sostenible ( $B O E$ núm. 55 , de 5 de marzo), en el que se afirma la necesidad de impulsar la eficiencia especialmente en el ámbito de la contratación pública y la colaboración entre el sector público y privado como «[...] elementos fundamentales de relación entre la Administración Pública y el tejido empresarial y, a la vez, como ámbitos en los que debe reforzarse la vinculación a parámetros de sostenibilidad económica [...]».

2 MiR PUIG, O. Globalización, Estado y Derecho. Las transformaciones recientes del Derecho administrativo, Thomson-Civitas, Madrid, 2004, p. 19.

3 GADEA Soler, E. «Estudio sobre el concepto de cooperativas: referencia a los principios cooperativos y su discutida vigencia», JADO, Boletín de la Academia Vasca de Derecho, núm. 17, Bilbao, 2009, pp. 177 a 183. ISSN: 1134 - 993X, Núm. 46/2012, Bilbao, págs. 185-199 
Una cooperativa se puede definir, por lo tanto, más que como una empresa, como una empresa en la que se participa. Se trata de una fórmula organizativa que tiene como rasgo diferencial la participación democrática y económica de sus miembros, cuyo estudio y análisis en profundidad permite explicar muchos otros fenómenos participativos ${ }^{4}$.

En este sentido, el presente trabajo propone una aproximación al significado, alcance y articulación de la participación del cooperativismo en las políticas públicas, como expresión del cambio de rol de los ciudadanos en su relación con los poderes públicos; unos ciudadanos, en definitiva, cada vez más exigentes a la hora de conocer, influir y formar parte de cuantas decisiones afectan al funcionamiento y la prestación de unos servicios públicos a cuyo mantenimiento contribuyen con sus impuestos.

\section{La participación en el Derecho administrativo}

\subsection{Significado de la participación ciudadana en la gestión pública}

La participación tiene diversos significados según cuál sea la realidad social, económica, política y cultural en la que se pretenda implantar. En algunos casos, el hecho de que se potencie formalmente el desarrollo de instrumentos de participación revela la inexistencia o, cuando menos la inoperancia, de las instituciones públicas. En otros casos, sin embargo, se articulan procedimientos e instrumentos de participación orientados, de facto, a ser utilizados únicamente por determinados grupos de poder, culpando a la generalidad de los ciudadanos de la debilidad democrática de las políticas públicas, consecuencia de su dejadez o desidia al no participar suficientemente en la vida política o social ${ }^{5}$.

La importancia de la participación en el Derecho administrativo ya fue puesta de manifiesto por FosHoff en su formulación de la Administración Prestacional, hacia la que las Administraciones Públicas han ido evolucionando a lo largo de los siglos XIX y XX. Así, en palabras de este autor «...la Administración aportadora de prestaciones se basa en la participación. El sentido del concepto de la procura existencial estriba

4 Véanse, en este sentido, las reflexiones de Coque MartíneZ, J. en cuanto afirma que tal conceptualización del cooperativismo «[...] permite distinguir entre cooperativas —empresas donde se participa - y no cooperativas —empresas donde no se hace o se hace deficientemente-, en Compartir soluciones: las cooperativas como factor de desarrollo en zonas desfavorecidas, Consejo Económico y Social, Madrid, 2005, pp. 18 a 21.

5 Arenilla Sáez, M. Crisis y reforma de la Administración Pública, Netbiblo, La Coruña, 2011, p. 123. 
en otorgar la protección del Derecho público a esa participación (...). El concepto de procura existencial sirve en primera línea para asegurar la participación [la cursiva no está en el original] del individuo en las prestaciones de la Administración...» ${ }^{6}$.

Ahora bien, ¿qué trascendencia jurídica tiene esta afirmación de la importancia de la participación de los ciudadanos en las políticas públicas? Las consecuencias jurídicas de esta afirmación son, básicamente, las tres siguientes.

En primer lugar, garantizar la intervención de los particulares, así como de profesionales y peritos especializados en los diferentes ámbitos de actuación pública, para dar cumplimiento efectivo a la previsión del artículo 9.2 de la Constitución en el que en el que «facilitar la participación de todos los ciudadanos en la vida política, económica, cultural y social» se define como una función de los poderes públicos ${ }^{7}$.

En segundo lugar, afianzar y consolidar la realización del principio democrático mediante la previsión de cauces de participación necesarios en los procesos de redacción, aprobación, ejecución y evaluación de las políticas públicas, al menos en cuanto se refiere al control de la discrecionalidad administrativa ${ }^{8}$.

6 Forshoff, E. Sociedad industrial y Administración Pública, Escuela Nacional de Administración Pública, Madrid, 1967, pp. 21 a 23.

7 En este sentido, nos adherimos a las reflexiones de DeLGADo BARrio en las que afirma que «... el artículo 9.2 es el fundamento genérico sobre el que la Jurisprudencia viene construyendo el principio de participación (...). Ciertamente, no existe hoy en nuestra sociedad un espíritu participativo, pero corresponde a los poderes públicos (...), a la Administración, utilizar al máximo las posibilidades que el ordenamiento jurídico ofrece a los ciudadanos para participar [a nuestro juicio, el ejercicio de la potestad planificadora es una de estas posibilidades] (...). Sobre la base de la importancia del planeamiento para asegurar un cierto nivel de calidad de vida, la doctrina y también la Jurisprudencia vienen destacando la necesidad de su legitimación democrática, lo que exige una participación ciudadana en el procedimiento a seguir para su elaboración [la cursiva no está en el original]», en "Reflexiones sobre el artículo 106.1. CE...», El control de la discrecionalidad del planeamiento urbanístico, Civitas, Madrid, 1993, pp. 2318 a 2321.

8 Véanse, entre otras, las consideraciones al respecto de DE LA CRUZ FERRER cuando afirma que «la participación (...) [en nuestra opinión, basta con la previsión de cauces de participación en la elaboración de los planes, proyectos y programas en los que se concreta el ejercicio de la potestad administrativa de planificación] contribuye directamente a fomentar un mejor ejercicio de la discrecionalidad administrativa, cuyo fin es encontrar la opción que mejor realice el interés general (...), la participación contribuye en un primer momento a la legalidad, acierto y oportunidad de las disposiciones...», en «Sobre el control... », op. cit., pp. 94 y 95. Para AlBERTI ROVIRA la participación implica la posibilidad de que tanto los particulares como los poderes públicos tengan una «oportunidad de pronunciarse y de intervenir con carácter sustantivo (...); debe establecerse un canal fluido y constante de información entre todas las partes implicadas, que permita la evaluación de los resultados y la regular revisión de los planes establecidos», en ISSN: 1134 - 993X, Núm. 46/2012, Bilbao, págs. 185-199 
En tercer y último lugar, poder condicionar a los poderes públicos pudiendo llegar, incluso, a hacerles cambiar o, al menos reconsiderar, sus criterios de actuación ${ }^{9}$.

En definitiva, y desde la perspectiva del Derecho administrativo, se puede calificar a la participación como la garantía última de la representación de los diferentes intereses, públicos o privados, implicados en la gestión y en la actuación pública ${ }^{10}$. Ello, con el propósito de construir

«La planificación en el federalismo cooperativo», Congreso de Derecho Público de la Economía, Servicio central de publicaciones del Gobierno Vasco, Vitoria-Gasteiz, 1988, p. 293. Igualmente, GARCÉS SANAGUSTín ha señalado que «... cada forma de Estado exige la participación de determinados agentes y la instauración de unos cauces de participación específicos (...). La forma democrática del Estado y el reconocimiento del pluralismo político que conlleva, acarrea la participación de agentes cualificados (...) que asumen el protagonismo y canalizan los anhelos de participación de los individuos y de los colectivos sociales (...). El Estado social también acarrea la existencia de unos entes específicos que articulan la participación social en la materia que representan, en muchos casos, un interlocutor válido ante la Administración y los colectivos sociales beneficiarios de los correspondientes sistemas prestacionales...», en Prestaciones sociales, financiación administrativa y derechos de los ciudadanos, McGraw Hill, Madrid, 1996, pp. 53 y 54; Del mismo modo, Sebastián Martín-Retortillo Baquer ha destacado «... en esta línea amplia de participación (...) la insistencia que se pone en las técnicas planificadoras (...). La planificación no es una técnica obsoleta, no es un instrumento autoritario, o disfuncional, del mismo modo que no está reñida la racionalidad con la libertad», en el «Prólogo» del libro de Sánchez Blanco, A. El sistema económico de la Constitución (participación institucional de las Autonomías territoriales y dinámica social en la economía), Civitas, Madrid, 1992, pp. 26 y 27.

9 En este sentido, Dromı ha dicho que «la primera base o condición de un plan es la participación universal, la cual debe organizarse de modo que el pueblo, sujeto y objeto de la administración democrática del desarrollo, sea parte de la dinámica del cambio y comparta su proceso a través de la consulta, la toma de decisión y la ejecución (...). La participación es un requisito fundamental para que los planes no se limiten a enumerar deseos de contenido y nivel puramente técnicos, sino que se nutran y apoyen en la opinión pública y resulten en consecuencia expresión de la voluntad de hacer del pueblo mismo como parte de la dinámica transformadora de un país o de una región...», Derecho administrativo económico, Astresa, Buenos Aires, 1983, p. 155.

10 Véanse, entre otros, GARCÉS SANAGUSTín se ha referido a la validez de la planificación como cauce de participación, al poner de manifiesto la importancia que, en este sentido, tiene la «la proliferación de técnicas de planificación y de concertación, con la consiguiente gestión indirecta o concertada de los servicios y de las organizaciones prestacionales que se constituyan y la inclusión, obviamente, de los mecanismos que permitan la representación de los diferentes intereses...», Prestaciones sociales, financiación administrativa y derechos de los ciudadanos, McGraw Hill, Madrid, 1986, pp. 64 y 65; ANDER-EGG ha indicado que la participación y el diálogo son «dos características fundamentales de una programación [a nuestro juicio, el término adecuado sería el de planificación] democrática y participativa (...). Participar es tomar parte en todo aquello en donde uno está implicado; dialogar es contar con la opinión de los otros y saber enriquecerse con las diferencias...», Introducción a la planificación, Humanitas, Buenos Aires, 1978, p. 141. 
una Administración Pública más próxima a los administrados y a sus necesidades, de tal forma que se asegure la salvaguarda y mejor y más efectiva realización de sus derechos e intereses legítimos ${ }^{11}$.

\subsection{Participación ciudadana en la planificación de las políticas públicas}

Tal y como se ha puesto de manifiesto antecedentemente, destaca la apuesta del Derecho administrativo actual por la configuración de un nuevo modelo de gestión democrática de la Administración Pública, en pro de su transformación en una institución más abierta y accesible a los ciudadanos. Se trata, en definitiva, de la introducción de un nuevo modelo de gestión pública que busca una creciente implicación de los ciudadanos en la acción de gobierno mediante el refuerzo y la educación de una ciudadanía activa, informada, participativa y corresponsable.

Destaca en este sentido, el Anteproyecto de Ley de Transparencia y Buen Gobierno del Gobierno Vasco que se plantea como objetivos fundamentales el fomento de la gestión coparticipada de los servicios

11 En este sentido, Martín Rebollo ha afirmado que «... la idea de participación conecta con el acercamiento entre el Estado y la Sociedad (...) y supone una modesta vía de superación del individualismo que ha impregnado el Derecho administrativo desde sus mismos orígenes históricos (...). La introducción de técnicas de participación ciudadana en los asuntos públicos allí donde esta participación sea posible y deseable. No para legitimar a la Administración sino como vía de integración social y de acercamiento a los ciudadanos. Las fórmulas participativas, que suelen ser más viables en las Administraciones menores, encuentran su justificación en la adopción de opciones discutibles de trascendencia, en la valoración de la oportunidad de algunas decisiones generales, en el diseño de los modelos urbanos, por poner algunos ejemplos (...). La participación funcional (...) supone una colaboración externa, desde fuera, a través de informaciones públicas, oficinas de iniciativas, acciones populares y otras formulas semejantes (...). Potenciando las correspondientes oficinas de iniciativas y reclamaciones y, sobre todo, asegurando la respuesta a cada ciudadano que las utilice (...). Este tipo de participación halla, quizá, su piedra de toque en la elaboración de disposiciones generales, planes y proyectos [la cursiva no está en el original], sobre todo en el ámbito municipal, donde es decisiva la generalización de encuestas previas (...) puesto que, una vez puesto en funcionamiento todo el complejo mecanismo de elaboración de un plan y lo que ello conlleva, difícilmente se rectifica sustancialmente en cuanto a sus opciones básicas, que son las que interesa cuestionar en este tipo de encuestas....», en El Derecho administrativo y las relaciones entre las Administraciones Públicas y los ciudadanos. Lección de apertura del Curso académico 1984-1985, Universidad de Extremadura, Cáceres, 1984, pp. 33 a 36. En el mismo sentido, PArejo Alfonso ha señalado que la planificación es «....una técnica deseable [para garantizar la participación] dados el crecimiento y la complejidad de las tareas administrativas...», en Estado social y Administración Pública. Los postulados constitucionales de la reforma administrativa, Civitas, Madrid, 1983, p. 110. 
públicos, mediante la participación de los ciudadanos en el proceso de planificación de las políticas públicas, es decir, desde el momento de su enunciado y definición hasta la evaluación de los resultados obtenidos con su ejecución o implementación ${ }^{12}$.

De este modo, se puede definir la planificación participativa como un enunciado normativo en virtud del cual se determinan las pautas y las directrices básicas que inspiran y condicionan la actuación, tanto de los poderes públicos como de los particulares, incluyendo las relaciones que se establezcan entre ellos; pautas y directrices que se materializan e instrumentan jurídicamente a través de los diferentes planes, proyectos y programas administrativos.

Además de las características propias de cualquiera de sus manifestaciones o expresiones, desde el punto de vista del Derecho administrativo la planificación tiene unas características propias y esenciales que la definen como una potestad pública. En este sentido, la planificación se puede definir como una de las facultades de actuación o prerrogativas que el ordenamiento jurídico atribuye a las Administraciones Públicas, revistiéndolas de un estatus especial de imperium derivado de su misión de servicio a la protección, garantía y realización del interés general ${ }^{13}$.

Se concluye, por tanto, la validez de la planificación como instrumento o técnica de participación de los ciudadanos en las diferentes políticas públicas, en garantía de la representación de diferentes sensi-

12 http://www.irekia.euskadi.net/es/news/11372-gobierno-vasco-presenta-anteproyecto-ley-transparencia-buen-gobierno

13 En este sentido y de acuerdo con el profesor GARCÍA DE ENTERRía cuando afirma que el Derecho «parte de una determinada realidad social a la que, en alguna forma, pretende reconfigurar 0 , en último extremo, fijar y sostener» en Democracia, jueces y control de la Administración, Civitas, Madrid, 4. ${ }^{a}$ ed. 1998, p. 112. Desde esta perspectiva, se puede afirmar que las características propias de la potestad administrativa de planificación son las siguientes: su normativismo, en tanto que en cada una de las manifestaciones instrumentales de la planificación se establecen pautas de comportamiento y directrices de actuación orientadas a la consecución de fines u objetivos concretos y que son susceptibles de vincular tanto a los poderes públicos como a los administrados; su virtualidad como cauce de participación tanto de los poderes públicos (trámite de audiencia) como de los particulares (información pública) y de determinados colectivos técnicos o peritos en el ámbito de la gestión administrativa y, finalmente, su instrumentalización para la ejecución de los principios constitucionales de objetividad, eficacia y coordinación de la actuación de las Administraciones Públicas. Véase lo señalado al respecto por el profesor BeRMEJO VerA en cuanto afirma que «[...] el reconocimiento de la planificación en sentido constitucional —refiriéndose a la planificación económicacomo potestad pública está orientada al logro de objetivos de interés general [...]», en Constitución y planificación hidrológica, Civitas, Madrid, 1995, p. 55. 
bilidades e intereses en la ejecución y evaluación de las precitadas políticas públicas.

Pues bien, el modelo de planificación participativa al que nos referimos tiene como punto de partida una intervención ciudadana que comienza en la fase de redacción y elaboración de las normas mediante jornadas de trabajo, foros y debates abiertos a la ciudadanía, que continúa en el momento del diseño de los concretos planes y estrategias singularizadas de la actuación pública y que, finalmente, culmina con el seguimiento y la evaluación del impacto producido por la implementación de las diferentes políticas públicas.

En este contexto, el mundo cooperativo destaca por su capacidad para impulsar y liderar procesos de planificación participativa dirigidos a la optimización y la prestación eficaz y eficiente de los servicios públicos, especialmente en relación con el desarrollo local y con el impulso del denominado tercer sector económico o economía social.

En el ámbito de la Comunidad Autónoma del País Vasco, la representación de cooperativismo en las políticas públicas se ha institucionalizado a través del Consejo Superior de Cooperativas de Euskadi, organismo público dotado de personalidad jurídica propia y plena capacidad de obrar que ha destacado desde su constitución en el año $1983^{14}$ como órgano de encuentro y diálogo entre la sociedad civil y las Administraciones Públicas, garantizando, o cuando menos potenciando, la participación del cooperativismo en las políticas públicas.

\section{Cooperativismo y participación pública}

\subsection{Aproximación al concepto jurídico básico de las cooperativas como empresas de participación}

De acuerdo con la declaración formulada en el año 1995 por la Alianza Cooperativa Internacional, el fenómeno cooperativista está basado en los valores de la autoayuda, autorresponsabilidad, democracia, igualdad, equidad y solidaridad.

En la actualidad, se acepta mayoritariamente la definición del artículo 1 de la Ley 4/1993, de 24 de julio, de Cooperativas de Euskadi15,

14 El Consejo Superior de Cooperativas de Euskadi tiene sus orígenes en el artículo 70 de la Ley 1/1982, de 11 de marzo, de Cooperativas de Euskadi y se constituyó formalmente el día 28 de enero de 1983.

15 BOPV núm. 135, de 19 de julio de 1993. 
según la cual la cooperativa es una empresa que tiene por objeto prioritario la promoción de actividades económicas y sociales de sus miembros y la satisfacción de sus necesidades con la participación activa de los mismos, observando los principios cooperativos y atendiendo a la comunidad de su entorno ${ }^{16}$.

En definitiva, lo que distingue o singulariza a la entidad cooperativa de otras personas jurídicas con carácter empresarial no es el tipo o clase de actividad a desarrollar, sino los principios inspiradores y rectores de su estructura y funcionamiento: los principios cooperativos revisados periódicamente por la $\mathrm{ACl}$ que diferencian a las cooperativas de cualquier otro tipo de empresas y que se concretan en los siguientes: la adhesión voluntaria y abierta de sus miembros, la gestión democrática por los socios, participación económica de los socios, autonomía e independencia, educación, formación e información, cooperación entre cooperativas e interés por la comunidad ${ }^{17}$.

Tanto la Ley 27/1999, de 16 de julio, de Cooperativas $^{18}$ como la $^{2}$ Ley 4/1993, de 24 de julio, de Cooperativas de Euskadi ${ }^{19}$, definen las Sociedades Cooperativas como sociedades integradas por personas que se asocian de forma voluntaria con el fin de desarrollar en común una o varias actividades de carácter empresarial, acogiéndose a un modelo organizativo al servicio de sus miembros, cuyo principal objetivo es la promoción de las actividades económicas y sociales de aquellos, para el desarrollo de una empresa de propiedad conjunta y gestión democrática, con plena observancia y respeto de los principios cooperativos en su estructuración y funcionamiento.

Sea cual fuere la actividad cooperativizada debe servir a una función social, entendida como satisfacción de alguna de las necesidades de promoción de un interés de carácter socioeconómico de sus miembros que se anteponga al interés de un concreto y determinado beneficio económico.

La Ley Vasca regula las diferentes clases de cooperativas en el capítulo I de su Título II, especificando que éstas además de someterse a los principios configuradores establecidos en la ley, están sujetas a la legislación específica que resulte en cada caso aplicable, en función de cuál sea la concreta actividad que a la que se dediquen.

16 GAdeA Soler, E. «Estudio sobre el concepto de cooperativa: referencia a los Principios cooperativos y a su discutida vigencia», JADO. Boletín de la Academia Vasca de Derecho, año VII, núm. 17, Bilbao, 2009, p. 170.

17 GADEA Soler, E. op. cit., pp. 177 a 183.

18 BOE núm. 170, de 17 de julio de 1999.

19 BOPV núm. 135, de 19 de julio de 1993. 
En el supuesto que nos ocupa, en relación con la participación del cooperativismo en las políticas públicas, destaca, por una parte, el papel que juegan las cooperativas en tanto experiencias organizativas que se distinguen por su esencia participativa, así como por su potencialidad como impulsoras del desarrollo local, su intenso arraigo al terreno, su tendencia a la creación de empleo estable, su flexibilidad para adaptarse a los cambios y su capacidad para integrarse en redes superiores ${ }^{20}$.

Por otra parte, merece asimismo significarse el impulso de las cooperativas, junto con las mutuas y otras asociaciones, a la institucionalización de la denominada economía social o tercer sector, para cuya consecución y efectiva realización resulta imprescindible la articulación de técnicas de participación y colaboración con el sector público ${ }^{21}$.

\subsection{Institucionalización de la participación del cooperativismo en las políticas públicas. El supuesto del Consejo Superior de Cooperativas de Euskadi}

El Consejo Superior de Cooperativas de Euskadi tiene sus orígenes en la Ley 1/1982, de 11 de febrero, sobre Cooperativas, en cuyo artículo 70 se le constituye calificándole como el «máximo órgano de representación y promoción de las cooperativas». Con el paso del tiempo, este organismo público ha ido cediendo su misión o función representativa a las diferentes Federaciones de Cooperativas de Euskadi que se han ido constituyendo paulatinamente.

A partir del año 1996, y como consecuencia de la creación de la Confederación de Cooperativas de Euskadi, el Consejo ha centrado su esfuerzo y actuación como órgano consultivo y de asesoramiento a las Administraciones Públicas Vascas en materia cooperativa.

La definición de su naturaleza jurídica, su organización, competencias y funcionamiento están regulados en la Ley 4/1993, de 24 de junio, de Cooperativas de Euskadi, desarrollada a estos efectos por el Decreto 213/1999, de 11 de mayo, por el que se regula el Consejo Superior de Cooperativas de Euskadi y por su Reglamento de Organización y Funcionamiento interno aprobado por Acuerdo adoptado en la sesión plenaria de 26 de julio de $1999^{22}$.

20 Coque Martínez, J. Compartir soluciones: las cooperativas como factor de desarroIlo en zonas desfavorecidas, Consejo Económico y Social, Madrid, 2005, pp. 13 y 14.

21 Zurbano, M.; Henry, G; Urzelal, A. El cuarto sector en Euskadi, Innobasque, Zamudio, 2012, pp. 51 a 57.

22 BOPV núm. 55, de 20 de marzo de 2000. 
La primera Ley Vasca de Cooperativas, Ley 1/1982, de 11 de marzo, en su Capítulo II, artículo 66 establecía como una de las funciones de la Administración Pública en relación con el cooperativismo la de la «promoción, el estímulo y el desarrollo de las cooperativa y de sus organismos de apoyo».

Para tal fin, y tal y como se ha puesto antecedentemente de manifiesto, la precitada Ley, en su artículo 70 creó el Consejo Superior de Cooperativas de Euskadi como órgano de naturaleza administrativa y de composición mixta, integrado por representantes del Gobierno y del Cooperativismo Vasco.

En este contexto, el 28 de enero de 1983, tuvo lugar la constitución formal del Consejo Superior de Cooperativas de Euskadi, como un «inestable» espacio de convergencia entre lo público y lo privado y como resultado, en definitiva, del trabajo desarrollado por una incipiente Administración Pública autonómica interesada en promover la mayor riqueza y justicia social posible. De este modo, la creación del Consejo Superior de Cooperativas de Euskadi hizo posible que el cooperativismo vasco tuviera presencia institucional y empezase a participar en las políticas públicas ${ }^{23}$.

Desde el momento de su constitución, y tras más de 25 años de historia, el Consejo Superior de Cooperativas de Euskadi, en su naturaleza de organismo público dependiente de la Administración autonómica ha asumido una función de representación, servicio y atención al cooperativismo como intermediario entre los intereses que tanto las cooperativas como la propia Administración autonómica han concertado en torno al proyecto cooperativo vasco 24 .

23 Molina Aparicio, F. Historia del Consejo Superior de Cooperativas de Euskadì, Consejo Superior de Cooperativas de Euskadi, Vitoria-Gasteiz, 2009, pp. 9 a 11.

24 En palabras de Molina APARICIO, «[...] el Consejo ha actuado siempre como un organismo vivo, en permanente transformación y adaptación, siempre atento a las necesidades del movimiento cooperativo. Ha dotado de vida a objetivos que sirven al cooperativismo sabiendo resituarse como institución, creando estructuras participativas hacía dentro y hacía fuera del movimiento cooperativo, caso de foros e instituciones de debate y reflexión [...]. De hecho, se ha convertido, en su faceta consultiva y de relación con la Administración en un órgano destinado no sólo a la respuesta y la solución de consultas y cuestiones, sino también en un órgano de propuesta, de proposición de reformas y nuevas iniciativas en beneficio del cooperativismo. Cuenta, para ello, con una ventaja sustancial: su condición de espacio de intercambio y conexión entre el sector cooperativo, la universidad y la Administración Pública. Esa confluencia entre los público y lo privado, lo económico, académico y administrativo, supone un valor añadido esencial para esta institución de cara a su futuro. Un valor que puede aportar como mesa y foro principal de reflexión sobre el cooperativismo y las instituciones vascas, así como instrumento adecuado para impulsar acuerdos entre los representantes de aquél y de la Administración.», en op. cit., pp. 128 y 129. 
A lo largo de toda su andadura, si algo hay que destacar de la actividad, y de la propia esencia, del Consejo Superior de Cooperativas de Euskadi es su virtualidad como órgano de participación, de encuentro y de diálogo entre la sociedad civil y las Administraciones y entidades del sector público, potenciando la presencia institucional del cooperativismo en las políticas públicas e impulsando la creación de foros de debate, participación y divulgación de los valores y principios cooperativis$\operatorname{tas}^{25}$.

A tal efecto, el Reglamento de Organización y Funcionamiento interno del Consejo Superior de Cooperativas de Euskadi, en su artículo 1, reafirma su naturaleza jurídica como Entidad Pública de carácter consultivo y asesor, dotado de personalidad jurídica propia y plena capacidad de obrar.

En cuanto a sus competencias concretas competencias generales, el artículo 4 del referido Reglamento de Organización y Funcionamiento interno, atribuye expresamente al Consejo las siguientes cinco funciones básicas: promoción, difusión, arbitraje, consulta y asesoramiento a las Administraciones Públicas Vascas en materia de cooperativismo y colaboración con el sector público. A continuación, y a fin de lograr una adecuada y efectiva realización de tales funciones básicas, el apartado 3 del precitado artículo 4 establece que el Consejo utilizará, como elemento instrumental esencial el de la potestad administrativa de planificación ${ }^{26}$.

De este modo, se dota al Consejo de ese imperium especial del que está investida la Administración Pública cuando actúa al servicio de la efectiva realización del interés general, mediante el reconocimiento de una potestad administrativa que destaca especialmente por su validez como cauce o mecanismo para la integración y participación del mundo cooperativo y sus intereses, en la gestión pública, especialmente en cuanto se refiere al desarrollo local y al impulso de la denominada economía social, o tercer sector económico.

25 Molina Aparicio, F. op. cit., p. 130.

26 En desarrollo de esta previsión, el artículo 4 del Reglamento de Organización y Funcionamiento interno establece que «la planificación se materializará en las modalidades de largo y corto plazo mediante, respectivamente, un Plan Estratégico trienal y un Plan de Gestión anula, que serán aprobados por el Pleno del Consejo a propuesta de su presidente y que contendrán necesariamente, además de las previsiones presupuestarias correspondientes, el programa de acciones a desarrollar en cada uno de los capítulos referentes a las funciones que le son propias. 


\section{A modo de conclusión}

En el contexto de un Estado social y democrático de derecho, la participación ciudadana y la transparencia de las políticas públicas se configuran como principios inherentes a la actuación de los poderes públicos, necesarios para garantizar una gestión administrativa eficiente, eficaz y capaz de responder a las expectativas y demandas de la sociedad 27.

En este sentido, se puede afirmar que el Derecho administrativo de nuestros días está inmerso en un proceso de transformación de las relaciones entre los ciudadanos y los poderes públicos que tiene como punto de partida y de llegada la consolidación de una Administración Pública transparente en su actuación y en la gestión de los intereses públicos, desde la planificación de las políticas públicas hasta su ejecución material en los diferentes ámbitos y sectores de actuación administrativa ${ }^{28}$.

El camino hacia la simplificación y la progresiva desburocratización de la organización y de la actuación de las Administraciones Públicas se configura en la actualidad como el reto más importante y significativo del Derecho administrativo de nuestro tiempo, en un entorno cada vez más participativo en el que los ciudadanos han dejado de ser meros receptores de los servicios públicos para pasar a asumir un rol cada vez más exigente con el modo, las circunstancias y los principios gestores que utilizan las Administraciones Públicas para prestarlos.

Para ello, y frente a los instrumentos y cauces tradicionales de participación ciudadana, tales como la consulta popular, la información y la audiencia pública o las iniciativas y propuestas ciudadanas, en los últimos tiempos se ha generalizado el desarrollo de procesos innovadores de planificación participativa, en coherencia con un modelo de gestión

27 En este sentido se ha pronunciado el profesor GARCíA MACHO cuando afirma expresamente que «[...] el principio de transparencia se ha convertido en el contexto de un Estado democrático y de derecho en un requisito necesario en los procedimientos de decisión administrativos y en los de elaboración de las leyes, si se pretende crear una estructura de inclusión del ciudadano en la toma de decisiones políticas y administrativas [...]», en GARCíA MACHO, R. "La transparencia en el sector público», en El derecho público de la crisis económica. Transparencia y sector público. Hacía un nuevo Derecho Administrativo», Instituto Nacional de Administración Pública, Madrid, 2011, p. 247.

28 Debe significarse en este sentido, que la propia Ley 30/1992, de 26 de noviembre, en su artículo 3.5 incluye el principio de transparencia entre los principios generales de funcionamiento de las Administraciones Públicas en su relación con los ciudadanos, de tal forma y manera que dicha determinación obliga a los poderes públicos a promover los cauces y procedimientos necesarios para su efectiva implementación y cumplimiento. 
pública participativo y de proximidad a los destinatarios y usuarios de los servicios públicos. Destacan como características más significativas de las referidas iniciativas de planificación participativa, aplicadas básicamente en el ámbito de las administraciones autonómicas y locales, las cuatro siguientes consideraciones:

- En primer lugar, la profundización participativa, indicativa del pluralismo y del número de participantes.

- En segundo lugar, la transversalidad de las experiencias planificadoras, en las que conviven diversos contenidos sustantivos, o sectores de actuación pública, con una pluralidad de redes de participantes o actores implicados.

- En tercer lugar, la innovación conceptual derivada de la novedad del mecanismo participativo.

- En cuarto, el impulso a redes de capital social, como capacidad de las iniciativas participativas para generar acuerdos, intercambios, cooperación y confianza entre los ciudadanos participantes.

- En quinto y último lugar, destacan los rendimientos sustantivos del proceso de planificación participativa, en la medida en que tienen como objetivo o finalidad la consecución de resultados en términos de transformación y optimización de la vida de los ciudadanos como destinatarios de los servicios públicos, cuya gestión se les participa.

En este contexto, el Consejo Superior de Cooperativas de Euskadi, fiel a su misión esencial de servicio y atención a las cooperativas, ha asumido un papel protagonista como intermediario e interlocutor entre éstas y las Administraciones Públicas Vascas, en representación y defensa de los intereses del cooperativismo y del proyecto cooperativo vasco en relación con todas las políticas públicas que les afectan. Para ello, el Consejo, en tanto que entidad pública dotada de personalidad jurídica propia y plena capacidad de obrar, ha actuado, desde el mismo momento de su constitución, como un organismo siempre atento a las necesidades del cooperativismo, creando estructuras participativas, tales como foros de debate y otras instituciones de estudio y reflexión ${ }^{29}$.

Por todo ello, se puede concluir, de manera incuestionable, que la esencia histórica de este organismo público ha sido su condición de órgano de participación del cooperativismo en las políticas públicas en tanto que espacio de encuentro entre el ámbito público y el privado;

29 Molina Aparicio, F.: Op. cit., pp. 128 y 129. 
un foro de intercambio de ideas, de promoción de iniciativas, de difusión, de educación y de información jurídica y técnica ${ }^{30}$.

\section{Apunte bibliográfico}

Arenilla Sáez, M. Crisis y reforma de la Administración Pública, Netbiblo, La Coruña, 2011.

Bermejo Vera, J. Constitución y planificación hidrológica, Civitas, Madrid, 1995.

Bermejo Vera, J.; Fernández Farreres, G. "Actuaciones administrativas aisladas versus planificación: modelo urbanístico y protección del patrimonio histórico-artístico», Cuadernos Aragoneses de Economía, 1981/1982.

Coque Martínez, J. Compartir soluciones: las cooperativas como factor de desarrollo en zonas desfavorecidas, Consejo Económico y Social, Madrid, 2005.

EMBID IRUjo, A. La planificación hidrológica: régimen jurídico, Tecnos, Madrid, 1991.

Forshoff; E. Sociedad industrial y Administración Pública, Escuela Nacional de Administración Pública, Madrid, 1967.

GADEA Soler, E. «Estudio sobre el concepto de cooperativas: referencia a los principios cooperativos y su discutida vigencia», JADO, Boletín de la Academia Vasca de Derecho, núm. 17, Bilbao, 2009.

Garcés Sanagustín. Prestaciones sociales, financiación administrativa y derechos de los ciudadanos, McGraw Hill, Madrid, 1996.

García de Enterría, E. Democracia, jueces y control de la Administración, Civitas, Madrid, 4. ${ }^{a}$ ed. 1998.

García MACHO, R. «La transparencia en el sector público», en El derecho público de la crisis económica. Transparencia y sector público. Hacía un nuevo Derecho Administrativo», Instituto Nacional de Administración Pública, Madrid, 2011.

Martín Rebollo, L. El Derecho administrativo y las relaciones entre las Administraciones Públicas y los ciudadanos. Lección de apertura del Curso académico 1984-1985, Universidad de Extremadura, Cáceres, 1984.

Martín Rebollo, L. Estado social y Administración Pública. Los postulados constitucionales de la reforma administrativa, Civitas, Madrid, 1983.

Martín-Retortillo Baquer, S., en el «Prólogo» del libro de Sánchez Blanco, A. El sistema económico de la Constitución (participación institucional de las Autonomías territoriales y dinámica social en la economía), Civitas, Madrid, 1992.

MIR PUIG, O. Globalización, Estado y Derecho. Las transformaciones recientes del Derecho administrativo, Thomson-Civitas, Madrid, 2004.

Molina Aparicio, F. Historia del Consejo Superior de Cooperativas de Euskadi, Consejo Superior de Cooperativas de Euskadi, Vitoria-Gasteiz, 2009.

ZuRbano, M.; HenRY, G; Urzelal, A. El cuarto sector en Euskadi, Innobasque, Zamudio, 2012.

30 Molina Aparicio, F. op. cit., p. 127. 